\title{
ANTIGEN RETRIEVAL BASED ON MICROWAVE-EXPOSURE IN IMMUNOSTAINS OF MYOSARCOMA TISSUES
}

\author{
TAtsuki OYAIZU ${ }^{1}$, Hideki TAKAHASHI ${ }^{1}$, Hideto SENZAKI ${ }^{1}$, YujI OISHI ${ }^{2}$, \\ AIRo TSUBURA ${ }^{1}$ AND Sotokichi MORII ${ }^{1}$

\begin{abstract}
Department of Pathology, Kansai Medical University ${ }^{1}$, Moriguchi, Osaka 570 and Department of Pathology,
\end{abstract} \\ Toxicology Research Laboratories, Fujisawa Pharmaceutical Co. ${ }^{2}$, Yodogawa, Osaka 532
}

Received for publication June 4, 1993 and in revised form June 24, 1993

\begin{abstract}
Antigen retrieval based on microwave-exposure of formalin-fixed, paraffin-embedded tissues in a metal solution of saturated lead thiocyanate or $20 \%$ zinc sulfate was investigated. Six leiomyosarcomas and 4 rhabdomyosarcomas were studied using the ABC method applying muscle-related markers. Compared with untreated control sections, vimentin and desmin showed increased staining after the exposure. However, myoglobin immunostaining was not improved. Therefore, some tissue antigens or epitopes were retrieved that were masked by formalin-fixation, but the retrieval was not universal.
\end{abstract}

Immunohistochemistry has contributed to a better understanding of cell type differentiation, tumor histogenesis, and predicting the prognosis $(1,2,5,14$, 18, 19). Despite these important benefits, there is ample evidence that formalin-fixation, the most common fixative, has a deleterious effect on the immunostaining of several antigens $(11,12)$. This may be caused by epitope masking, probably because of cross-linking of proteins around the antigenic site (4). In addition, the process responsible for the masking of the antigenicity is a progressive one that is enhanced by prolonged immersion in formalin (3). Therefore, interpretation is often difficult when negative immunostaining occurs. These results cannot clarify whether the cells do not contain an antigen (or the antigen level is below the detection sensitivity of the procedure), or whether the antigenicity was lost. Although many antibodies which can recognize formalin-resistant epitopes in immunohistochemical procedures have been developed, they have not been entirely satisfactory in resolving all problems.

Predigestion of formalin-fixed tissue sections with protease enhanced the immunostaining of several antigens by unmasking antigenic sites, but false negatives or no enhancement has been observed with others $(3,8,13)$. Recently, a method for antigen

Address for reprints: Tatsuki Oyaizu, M.D., Department of Pathology, Kansai Medical University, Fumizonocho 1, Moriguchi, Osaka 570, Japan. retrieval in formalin-fixed, paraffin-embedded tissue sections has been described (15). It is based on a microwave-exposure of tissue sections to temperatures of up to $100^{\circ} \mathrm{C}$ in the presence of metal solutions. In this study, we evaluated this new method in the immunostaining of muscle-related markers in formalinfixed, paraffin-embedded myosarcoma tissues.

\section{MATERIALS AND METHODS}

\section{Tissue Sections}

Six samples of leiomyosarcoma (LMS) and 4 of rhabdomyosarcoma (RMS) were obtained from the Kansai Medical University Hospital or the Saiseikai Nakatsu Hospital. Five LMS specimens and 1 of RMS were from surgery, and the remaining 5 were from autopsy. All tumor tissues were routinely fixed in $10 \%$ formalin within 1 week, and embedded in paraffin. All diagnose were based upon the HE-stained sections. Serial sections of $4 \mu \mathrm{m}$ were cut and mounted on aminopropyltriethoxysilane-coated slides (Matsunami Glass, Osaka, Japan).

\section{Tissue Antigen Retrieval}

The slightly modified protocol, originally described by Shi et al. (15), was as follows: The tissue sections on slides were deparaffinized, dehydrated, rinsed in deionized water (DM), and incubated in $3 \% \mathrm{H}_{2} \mathrm{O}_{2}$ in DW for $10 \mathrm{~min}$ to block endogenous peroxidase. Subsequently, the slides were washed with DW for $5 \mathrm{~min}$ and placed in polycarbonate staining jars 
(Kartell, Italy) filled with either DW, or a metal solution of saturated lead thiocyanate or $20 \%$ zinc sulfate. The jars were then covered and heated in a microwave oven (Mitsubishi, Japan) at $700 \mathrm{~W}$ for $5 \mathrm{~min}$ after the solution started to boil. The fluid level in the jars was then checked, and DW was added to the initial level before a further $5 \mathrm{~min}$ microwave-exposure. Thereafter, the slides were immediately put into warm $\left(60^{\circ} \mathrm{C}\right) \mathrm{DW}$, and allowed to cool for $15 \mathrm{~min}$ at room temperature. Slides were rinsed twice in DW for $5 \mathrm{~min}$, and washed in $0.05 \mathrm{M}$ Tris- $\mathrm{HCl}$ buffered saline, $\mathrm{pH} 7.6$, (TBS) for 5 min. These slides and serially cut untreated sections were immunohistochemically stained.

\section{Immunohistochemistry}

Antibodies and the antiserum, their specificity, clone designation, source and dilution are listed in Table 1. Using Vectastain ABC Kits (Vector Laboratories, Burlin game, CA, USA), immunohistochemical staining proceeded according to the manufacturer's instructions. Briefly, sections were incubated in the blocking reagent (normal horse or goat

TABLE 1. Antibodies and antiserum used in this study

\begin{tabular}{lccc}
\hline \multicolumn{1}{c}{ Specificity } & Glone designation & Source & Dilution \\
\hline Vimentin & V9 & DAKO & $1: 500$ \\
Desmin & D33 & DAKO & $1: 100$ \\
Myoglobin $^{1}$ & & DAKO & $1: 1000$ \\
\hline
\end{tabular}

1 Antiserum serum) for $20 \mathrm{~min}$, then with optimized diluted primary antibodies, for either $60 \mathrm{~min}$ at $37^{\circ} \mathrm{C}$ or overnight at $4^{\circ} \mathrm{C}$. Subsequently, the link antibody (biotinylated anti-immunoglobulins) and the labeling complex (avidin conjugated to horseradish peroxidase) were added. The reaction products were visualized with DAB (Wako Pure Chemical, Osaka, Japan). Sections were counterstained with Gill hematoxylin. In the negative controls, non-immune mouse or rabbit sera replaced the specific antibody or antiserum.

We then compared the effect of boiling time $(5,10$ and $15 \mathrm{~min}$ ), and the solutions (DW, saturated lead thiocyanate, and $20 \%$ zinc sulfate) in the immunohistochemical staining of vimentin.

\section{RESULTS}

Vimentin staining intensity was increased compared with untreated sections. Particularly, under the same boiling time, the saturated lead thiocyanate effected more intense staining than zinc sulfate or DW. Prolonged boiling for $10-15 \mathrm{~min}$ introduced more intense immunostaining than after 5 min (Fig. 1; Table 2). The background was reduced more when the sections were incubated in the primary antibody for $60 \mathrm{~min}$ at $37^{\circ} \mathrm{C}$ than overnight at $4^{\circ} \mathrm{C}$. Sometimes, the lead thiocyanate caused non-specific nuclear staining and diffuse crystal precipitates throughout the section. Insoluble crystal precipitates were formed when the lead thiocyanate was mixed with buffer. This contamination was eliminated by washing in heated DW $\left(60^{\circ} \mathrm{C}\right)$ just after microwave-
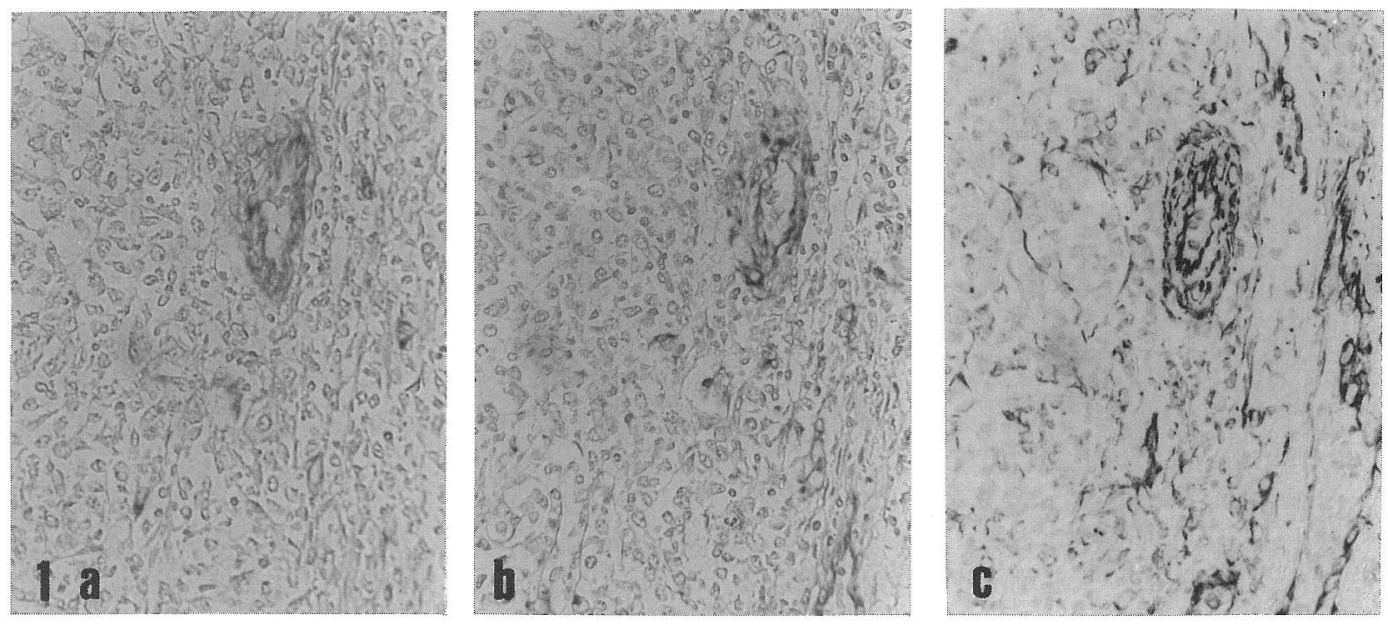

FIGS. 1a-c. The influence of the boiling solutions on antigen retrieval in vimentin immunohistochemistry, using a monoclonal antibody to vimentin within formalin-fixed, paraffin-embedded LMS sections. (a) $\mathrm{DW}$, (b) $\mathrm{ZnSO}_{4},(\mathrm{c}) \mathrm{Pb}(\mathrm{SCN})_{2}$, all for 10 min. Vimentin staining was significantly enhanced using the saturated lead thiocyanate (Fig. 1c). Original magnification: $\times 200$ 
heating in the metal solution, followed by sufficient washing in DW then with TBS. The endogenous peroxidase activity was also reduced in this manner. Considering these results, saturated lead thiocyanate with boiling for $10 \mathrm{~min}$ followed by sufficient washing gave satisfactory results. Applying this method, the immunoreactivity of 6 LMS and 4 RMS samples are indicated in Table 3.

Vimentin immunostaining was significantly increased after the procedure. The vast majority of tumor cells in both LMS and RMS were positively stained, and the staining was evenly distributed throughout the tumor tissues as well as in adjacent intermingled vessels (Fig. 2). Positive desmin staining was sometimes enhanced (Fig. 3). However, the immunoreactivity of myoglobin in tumor cells was not enhanced even after boiling for $15 \mathrm{~min}$, though it was

TABLE 2. Enhancement by tissue antigen retrieval in vimentin immunohistochemistry

\begin{tabular}{lccc}
\hline \multirow{2}{*}{ Solution } & \multicolumn{3}{c}{ Time $(\min )^{\mathrm{a}}$} \\
\cline { 2 - 4 } & $5 \mathrm{~min}$ & $10 \mathrm{~min}$ & $15 \mathrm{~min}$ \\
\hline $\mathrm{Pb}(\mathrm{SCN})_{2}$ & $H^{\mathrm{b}}$ & \# & W \\
$\mathrm{ZnSO}_{4}$ & + & + & + \\
Deionized water & + & + & + \\
\hline
\end{tabular}

a Time of microwave-exposure after the boiling point.

b Slight, moderate and predominant enhancement in vimentin immunoreactivity are expressed as scales of,$+ H$ and H. enhanced in some normal muscle cells (Fig. 4).

\section{DISCUSSION}

Formalin fixative has been routinely used due to its excellent preservation of tissue structures. However, in immunohistochemistry, it occasionally causes problems in the preservation of antigenicity. The reactive aldehyde group of formaldehyde binds to amine groups on the polypeptide backbone and amino acid side chains, leaving the potential antigenic sites masked (9). Shi et al. developed a method for antigen retrieval in formalin-fixed, paraffin-embedded tissue sections using metal solutions in combination with microwave oven heating. They found that heating, microwave-exposure, or the presence of heavy metal solution alone enhanced the immunohistochemical staining of a variety of tissue antigens (15). The mechanism of antigen recovery might be associated with alterations in the cross-linking of proteins caused by formaldehyde, since this treatment does not affect the alcohol-fixed tissues. Protease digestion may be based upon a similar mechanism (13). Protease digestion could improve the staining of some antibodies, such as to keratins, but did not exhibit sufficient reaction on other antigens such as vimentin. Autoclaving sections immersed in distilled water (hydrated autoclaving) recovered the immunoreactivity to antitau antibody, in which the heating might have induced a denaturation of formalin-fixed tissue protein (16). Microwave-exposure in DW enhanced the im-

TABLE 3. Comparison of immunoreactivity in tissue sections of leiomyosarcoma and rhabdomyosarcoma with or without tissue antigen retrieval ${ }^{1}$

\begin{tabular}{|c|c|c|c|c|c|c|c|}
\hline \multirow{2}{*}{ Case } & \multirow{2}{*}{$\begin{array}{c}\text { Antigens } \\
\text { Treatment }\end{array}$} & \multicolumn{2}{|c|}{ Vimentin } & \multicolumn{2}{|c|}{ Desmin } & \multicolumn{2}{|c|}{ Myoglobin } \\
\hline & & $(-)$ & $(+)$ & $(-)$ & $(+)$ & $(-)$ & $(+)$ \\
\hline $\mathrm{LMS}^{2}-1$ & & $-1-4$ & $+1-$ & $-1-$ & $+1-$ & $-1-$ & $-1-$ \\
\hline LMS-2 & & $+1-$ & $+1+$ & $+1+$ & $+1+$ & $-1-$ & $-1-$ \\
\hline LMS-3 & & $-1-$ & $+1+$ & $+1-$ & $+1-$ & $-1-$ & $-1-$ \\
\hline LMS-4 & & $-1-$ & $+1+$ & $-1-$ & $+1-$ & $+1-$ & $-1-$ \\
\hline LMS-5 & & $-1-$ & $+1+$ & $+1+$ & $+/ H$ & $+1-$ & $+1-$ \\
\hline LMS- 6 & & $-1-$ & $+1+$ & $+1+$ & $+1+$ & $+1-$ & $+1-$ \\
\hline $\mathrm{RMS}^{3}-1$ & & $-1-$ & $+1-$ & $-1-$ & $-1-$ & $-1-$ & $-1-$ \\
\hline RMS-2 & & $-1-$ & $+1+$ & $-1-$ & $+1-$ & $+1-$ & $+1-$ \\
\hline RMS-3 & & $-1-$ & $-1+$ & $-1-$ & $+1+$ & $+/+$ & $\mathrm{HI}+$ \\
\hline RMS-4 & & $-1-$ & $+1+$ & $+1-$ & $+1-$ & $+1-$ & $H /-$ \\
\hline
\end{tabular}

1 Routinely prepared and deparaffinized sections were incubated in boiling $\mathrm{Pb}(\mathrm{SCN})_{2}$ for $10 \mathrm{~min}$ after blocking endogenous peroxidase, then thoroughly washed in DW.

2 LMS: Leiomyosarcoma.

3 RMS: Rhabdomyosarcoma.

4 Normal/tumor cells. Immunoreactivity was scored on a scale of - to $H$. 

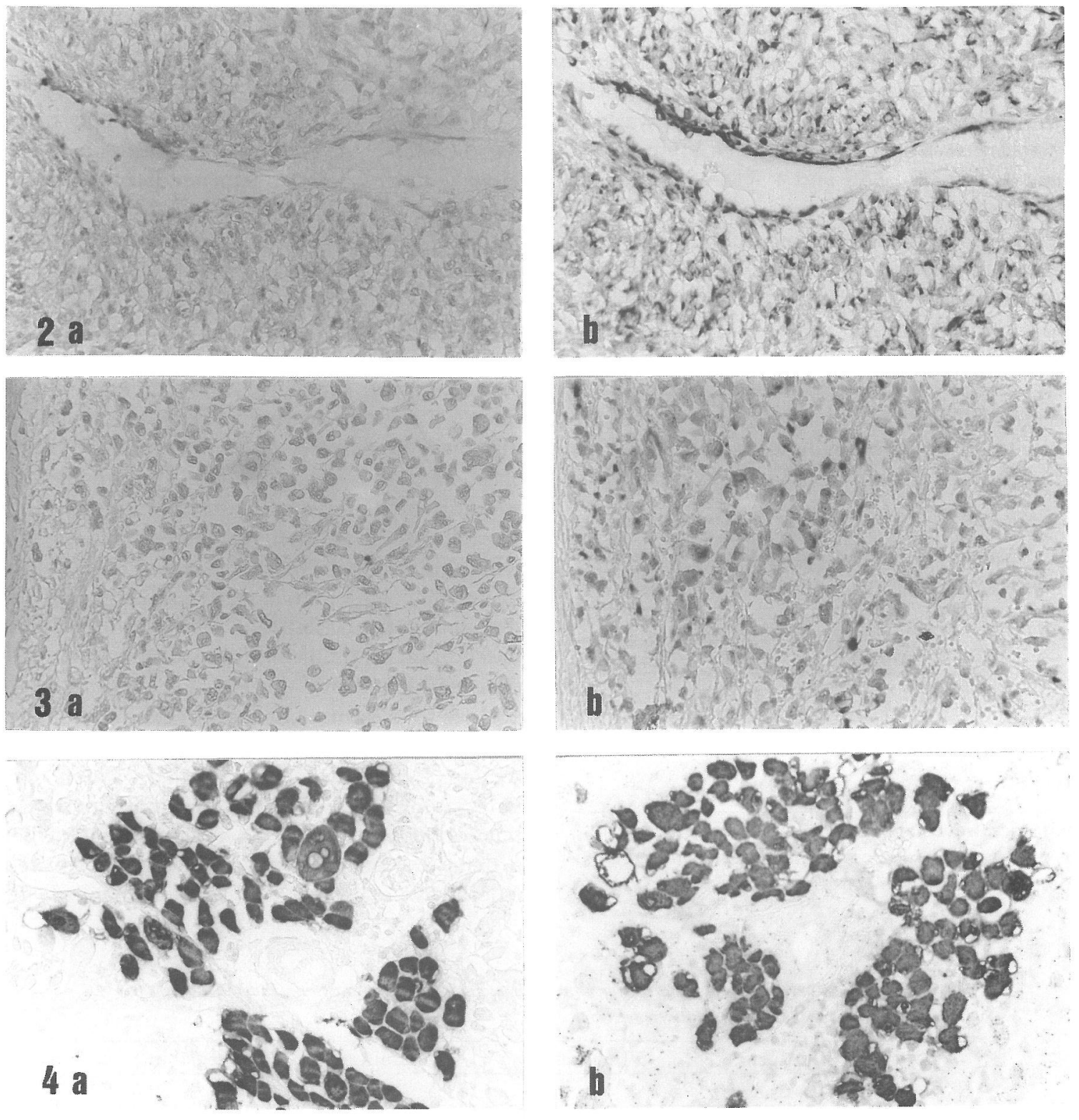

Figs. 2a, b. A monoclonal antibody to vimentin demonstrated a significant increase of the immunostaining in formalin-fixed, paraffin-embedded sections of LMS after tissue antigen retrieval (Fig. 2b). a. No treatment. b. After treatment. Original magnification: $\times 400$

FIGS. 3a, b. A monoclonal antibody to desmin showed a moderate increase of the immunostaining in formalin-fixed, paraffinembedded sections of LMS after treatment (Fig. 3b). a. No treatment. b. After treatment. Original magnification: $\times 200$

Figs. $4 a, b$. The immunoreactivity of antiserum to myoglobin was not enhanced even after treatment. a. No treatment. b. After treatment. Original magnification: $\times 20$

munoreactivity, but metal solutions were more effective. Heavy metal salts act as protein precipitating agents, and protein-precipitating fixatives frequently preserve more antigens than cross-linking aldehyde fixatives $(7,9)$. Cross-linking of proteins alone could not explain the mechanism of the antigen recovery. Both heating and the presence of metal solutions might mainly affect this mechanism. Additionally, the physical effect of the boiling upon the antigenitic sites might play a principal part as well as heating. The influence of various solutions under similar conditions consisting of heat and a boiling period should be 
evaluated.

Formalin-fixation is used almost universally by pathologists, and there is no standard method of fixation that can be applied to tissues submitted for immunohistochemical analysis. Tissue antigen retrieval did recover and/or retrieve the epitopes masked by formalin-fixation, and was applicable to some antibodies.

An enhanced immunohistochemical procedure to detect proliferating cell nuclear antigen (PCNA) has also been reported that was similarly based on microwave-exposure in combination with a metal solution $(6,20)$. The antigenicity of desmin is not well preserved in formalin-fixed specimens (11). Myoglobin is a specific marker for striated muscles $(10$, 17). Detection of intermediate filaments as vimentin and desmin is particularly difficult in routinely fixed tissues, and the enhancement and/or antigen retrieval of immunoreactivity was not always consistent even after protease digestion.

In conclusion, striking immunostaining retrieval was obtained with a monoclonal antibody to vimentin. Tissue antigen retrieval more intensely immunostained desmin. We could not however, enhance the retrieval of myoglobin immunostaining.

\section{REFERENCES}

1. Altmannsberger, M., Osborn, M. and Schauer, A.: Antibodies to different intermediate filament proteins: Cell type-specific markers on paraffin-embedded human tissues. Lab. Invest. 45; 427-434, 1981.

2. Altmannsberger, M., Weber, K., Droste, R. and Osborn, M.: Desmin is a specific marker for rhabdomyosarcomas of human and rat origin. Am. J. Pathol. 118; 85-95, 1985.

3. Battifora, H. and Kopinski, M.: The influence of protease digestion and duration of fixation on the immunostaining of keratins: A comparison of formalin and ethanol fixation. J. Histochem. Cytochem. 34; 1095-1100, 1986.

4. Fox, C. H., Johnson, F. B., Whiting, J. and Roller, P. P.: Formaldehyde fixation. J. Histochem. Cytochem. 33; 845-853, 1985.

5. Gabbiani, G., Kapanci, Y. and Barazzone, P.: Immunohistochemical identification of intermediate-sized filaments in human neoplastic cells: A diagnostic aid for surgical pathologist. Am. J. Pathol. 104; 206-216, 1981.

6. Greenwell, A., Foley, J. F. and Maronpot, R. R.: An enhancement method for immunohistochemical staining of proliferating cell nuclear antigen in archival rodent tissues. Cancer Letters. 59; 251-256, 1991.

7. Hermann, G. E., Chlipapa, E., Bochenski, G., Sabin, L. and Elfont, E.: Zinc formalin fixative for automated tissue processing. J. Histotechnol. 11; 85-91, 1988.
8. Huang, S. N., Minassian, H. and More, J. D.: Application of immunofluorescent staining on paraffin sections improved by trypsin digestion. Lab. Invest. 35; 383-390, 1976.

9. Jones, M. D., Banks, P. M. and Caron, Bl.: Transitional metal salts as adjuncts to formalin for tissue fixation. Lab. Invest. 44; 32A, 1981.

10. Mukai, M., Rosai, J. and Hallaway, B. E.: Localization of myoglobin in normal and neoplastic human skeletal muscle cells using immunoperoxidase method. Am. J. Surg. Pathol. 3; 373-376, 1979.

11. Mukai, M., Torikata, C., Shimoda, T. and Iri, H.: Alveolar soft part sarcoma: Assessment of immunohistochemical demonstration of desmin using paraffin sections and frozen sections. Virchows Arch. A. 414; 503-509, 1989.

12. Nagel, R. B., McDaniel, K. M., Clark, V. A. and Payne, C. M.: The use of antikeratin antibodies in the diagnosis of human neoplasm. Am. J. Clin. Pathol. 79; 458-466, 1983.

13. Ordóñez, N. G., Manning, Jr, J. T. and Brooks, T. E.: Effect of trypsinization on the immunostaining of formalin-fixed, paraffin-embedded tissues. Am. J. Surg. Pathol. 12; 1212-1219, 1988.

14. Osborn, M. and Weber, K.: Tumor diagnosis by intermediate filament typing: A novel tool for surgical pathology. Lab. Invest. 48; 372-394, 1983.

15. Shi, S.-R., Key, M. E. and Kalra, K.: Antigen retrieval in formalin-fixed, paraffin-embedded tissues: An enhancement method for immunohistochemical staining based on microwave oven heating of tissue sections. J. Histochem. Cytochem. 39; 741-748, 1991.

16. Shin, S.-R., Iwaki, T., Kitamoto, T. and Tateishi, J.: Method in laboratory investigation: Hydrated autoclave pretreatment enhances tau immunoreactivity in formalinfixed normal and Alzheimer's disease brain tissues. Lab. Invest. 64; 693-702, 1991.

17. Skalli, O., Ropraz, P., Trzeciak, A., Benzonana, G., Gillessen, D. and Gabbiani, G.: A monoclonal antibody against $\alpha$-smooth muscle actin: A new probe for smooth muscle differentiation. J. Cell. Biol. 103; 2787-2796, 1986.

18. Skalli, O., Gabbiani, G., Babaïi, F., Seemayer, T. A., Pizzolato, G. and Schürch, W.: Intermediate filament proteins and actin isoforms as markers for soft tissue tumor differentiation and origin: II. Rhabdomyosarcomas. Am. J. Pathol. 130; 515-531, 1988.

19. Schürch, W., Skalli, O., Seemayer, T. A. and Gabbiani, G.: Intermediate filament proteins and actin isoforms as markers for soft tissue tumor differentiation and origin: I. Smooth muscle tumors. Am. J. Pathol. 128; 91-103, 1987.

20. Takahashi, H., Oishi, Y., Chuang, S.-S. and Morii, S.: Effect of tissue fixation and processing on proliferating cell nuclear antigen (PCNA) immunohistochemistry. Acta Pathol. Jpn. 42; 621-623, 1992. 